\title{
China e a (In)Segurança Energética: Planejamento político com foco na sustentabilidade, competitividade e garantia de suprimentos. \\ DOI 10.29327/230731.12.24-7
}

Tatiana Molina ${ }^{1}$, Luiz Pedone ${ }^{2}$

Resumo: O presente artigo aborda o tema Segurança Energética, com foco na problemática chinesa. Com o objetivo de analisar como o país está elaborando estratégias que foquem na auto-suficiência e no mix energético, foi realizada análise bibliográfica e documental sobre as políticas de desenvolvimento de energia elaboradas visando a minimização da dependência chinesa do petróleo, carvão, gás natural, e o aumento do investimento em energias renováveis. Foi ainda utilizado o método interrogativo de investigação e a pesquisa exploratória. Como segunda economia mundial, a China precisa manter constante seu nível de aquisição e produção de energia para que não esteja sujeita às variáveis internacionais e, com isso, não desmorone seu processo de desenvolvimento interno e ascensão internacional. $O$ trabalho defende que somente a variedade energética é capaz de garantir a suplementação da demanda e, assim, assegurar os rumos satisfatórios do desenvolvimento econômico. Nesse sentido, a Lei de Energia Renovável (RPC, 2006), serviu como base para os objetivos de redução da poluição do ar, proteção da saúde humana e do meio ambiente e expansão do fornecimento de energia nas áreas rurais. A Lei foi também pilar para várias agências governamentais e autoridades locais que implementaram regulamentos para 0 avanço de políticas de pesquisa e desenvolvimento de energias renováveis. Como um tema sempre atual, Segurança Energética compreende em si um conjunto de ações que devem ser orientadas pelo estado a fim de assegurar suas garantias básicas de energia a qual nenhuma nação pode se esquivar.

Palavras-chave: Desenvolvimento Econômico; China; Segurança Energética; Mix de Energias

\section{Introdução}

O fim da Segunda Guerra Mundial e o início da Guerra Fria (1945-1991), marcaram uma fase de disputa entre as duas grandes potências da época, Estados Unidos e URSS. Ainda em 1945 surgiu a disciplina International Security Studies (ISS), que definiu o termo segurança (Buzan e Hansen, 2009).

1 Professora na Lanzhou Jiaotong University - Gansu, China. Doutora em Ciência Politica, Mestre em Estudos Estratégicos da Segurança e da Defesa, Especialista em Relações Internacionais, Jornalista. Membro do Grupo de Pesquisa Defesa, C\&T e Políticas Públicas e C\&T \{Laboratório Defesa\&Política[s]\} do Instituto de Estudos Estratégicos (INEST) da Universidade Federal Fluminense (UFF).

2 Professor Associado de Relações Internacionais, Instituto de Estudos Estratégicos, Universidade Federal fluminense (UFF). Coordenador do Grupo de Pesquisa Defesa, C\&T e Políticas Públicas e C\&T \{Laboratório Defesa\&Política[s]\} do Instituto de Estudos Estratégicos 


\section{Universidade Federal Fluminense Instituto de Estudos Estratégicos}

Marcado por rivalidades em todas as esferas, notadamente a nuclear, 0 momento propiciava uma conceituação pautada no poderio militar, na ideia de que segurança fosse a derivação do poder emanado pelos estados (Stone, 2009). Com o fim da Guerra Fria, problemas provenientes de países antes sob influência dos EUA e URSS chamaram a atenção para a real situação de décadas de exploração e negligência. Embates étnicos, religiosos, ambientais e de direitos humanos extrapolaram as fronteiras e fizeram o mundo reconhecer que segurança deveria ter um conceito mais amplo. Não era mais somente uma questão militar; segurança estava impregnada nos aspectos sociais, políticos, econômicos e na relação entre os estados (ibidem).

Para alguns estudiosos, abranger outras questões na agenda de segurança fugia do foco original do estudo que tinha como fonte o conceito defendido pela Teoria Realista. Entretanto, a partir da década de 1980, pesquisadores viram a necessidade de incluir no debate áreas como a ambiental, a econômica e assuntos como saúde, desenvolvimento e gênero. Atualmente, esses temas dificilmente poderiam ser separados da securitização porque a própria agenda de segurança internacional tem mudado através dos anos (ibidem). Sendo assim, para Buzan (1991):

Segurança é interpretada como a busca por liberdade, a partir de ameaças, e
a capacidade dos estados e da sociedade de manter sua identidade
independente e sua integridade contra as forças que eles veem como hostil. A
linha de fundo da segurança é a sobrevivência, mas é também razoável incluir
preocupações sobre as condições da existência. Consideravelmente, onde
esta gama de preocupações deixa de merecer a urgência do rótulo de
"segurança" (o qual identifica ameaças como significativo o suficiente para
justificar a ação de emergência e medidas excepcionais incluindo o uso da
força) e tornar-se parte do dia a dia das incertezas da vida, é uma das
dificuldades do conceito.

Segundo Stone (2009), Buzan se interessa por todos os ângulos da questão segurança e, em sua visão construtivista, segurança não é um conceito estabelecido, mas vai sendo delimitado ao se considerar cada elemento integrado ao assunto. O tema deve ser analisado observando-se os aspectos que contribuem e/ou o afetam como os setores político, militar, econômico, social e ambiental. 


\section{Segurança Energética (SE)}

Todos os países estão vulneráveis ao fornecimento de energia. Para o modo de vida como conhecemos hoje, a possibilidade de uma ameaça à segurança energética se torna um dilema de segurança. O tema extrapola as fronteiras nacionais, tem relação imediata com o relacionamento entre os países e está ligado a uma variedade de ameaças (Yergin, 2014). Sendo assim, Segurança Energética (SE) abrange um conceito multidimensional que inclui sustentabilidade, competitividade e garantia de suprimentos. Envolve setores da economia e da política (Baumann, 2008) com necessidade de planejamento e desenvolvimento de estratégias. É uma preocupação constante dos estados, pois estes precisam assegurar sua demanda e de um mínimo de confiança de que terão acesso às fontes de energia.

Torna-se necessário salientar para a diferença entre segurança energética e independência energética. A primeira trata da confiança no acesso à energia, mas não de independência do mercado global. Por acesso garantido entende-se como o suprimento da demanda devido ao país ser também o produtor, possuir infraestrutura ou ter diferentes fontes energéticas. Assegurar Segurança Energética é de responsabilidade governamental, já que esta é precondição para o desenvolvimento econômico. Segurança social e estabilidade são valores fundamentais para qualquer sociedade. Segurança Energética envolve, então, "uma gama substancial de preocupações sobre as condições de existência" (ibidem).

De acordo com Baumann (2008), a definição de Segurança Energética passa por dimensões de política interna e externa, econômica, geopolítica e de segurança. Política e econômica porque envolve gestão e investimento; geopolítica e de segurança por estarem intimamente ligadas ao relacionamento entre os estados, pela necessidade de garantir a salvaguarda dos suprimentos assim como seu transporte. O tema SE e seus cenários político, econômico e geopolítico se afetam e se complementam não somente pela complicada definição sobre qual área principal o tema está submetido, mas também porque extrapola todas as vertentes tornando-se uma questão de sobrevivência dos 


\section{Universidade Federal Fluminense Instituto de Estudos Estratégicos}

estados. Segundo Buzan (1991), política energética deve ser securitizada e compreendida como uma questão de segurança caso queira-se manter as conquistas individuais e de estado como o desenvolvimento econômico, a estabilidade política e a segurança da sociedade (ibidem).

Desde que o tema começou a ganhar atenção, a definição de SE tem se mostrado complexa. Para Daniel Yergin (2009), é "a capacidade de se conseguir suprimento suficiente por um preço justo". Para Karaca (2012), SE significa "A aquisição de energia sem nenhum problema e irrestrito acesso a fontes energéticas". Todavia, além de vago e limitado, essas definições parecem simplificar as relações entre importadores e exportadores. Elas não atendem à dinâmica das relações internacionais, principalmente no que tange à geopolítica, e não levam em conta os embates, conflitos e fricções entre estados (ibidem). Outro ponto é que a partir dessas definições, presume-se que quem compra exerce mais influência sobre quem vende e que o mercado é quase sempre estável, não sofrendo especulações (ibidem). As definições também não examinam a formação de cartel e variáveis como crises internacionais e problemas ambientais. A diversificação de exportadores, apesar de mais segura, não garante uma suplementação suficiente porque ainda assim o mercado é instável. Focando no preço e na garantia da suplementação, foca-se no exterior, no outro, e não no que o próprio estado pode e deve fazer para garantir sua reserva e, com isso, garantir sua independência, ainda que limitada, frente ao mercado. Não se leva em conta a autossuficiência, a diversificação e/ou o mix energético.

A definição também não considera o aspecto político da SE onde os estados percebem sua dependência como uma ameaça (Palonkorpi, 2006). Essa percepção se torna mais clara ao se constatar controvérsias e conflitos entre os países, a citar como exemplo o caso da Rússia e da Ucrânia, em 2014, onde a Rússia cortou o fornecimento de gás para a Ucrânia. A concentração de suprimento de petróleo e gás, sob tutela de poucos estados, reforça a dependência e sujeita os compradores à adversidades políticas e econômicas. Paul Roberts (ibidem) argumenta:

A falta de segurança energética significa que o impulso da industrialização e da modernidade sofrerá uma parada e a própria sobrevivência tornar-se-á muito menos segura. 


\section{Universidade Federal Fluminense Instituto de Estudos Estratégicos}

A Agência Internacional de Energia (AIE) define segurança energética como "A disponibilidade ininterrupta de fontes de energia a um preço acessível"(AIE, 2015) e analisa que:

A segurança energética tem muitos aspectos: a longo prazo lida principalmente com investimentos em tempo hábil para fornecer energia em consonância com a evolução econômica e as necessidades ambientais. Por outro lado, a segurança energética de curto prazo centra-se na capacidade do sistema de energia para reagir prontamente a mudanças súbitas no balanço de oferta e demanda.

Segurança Energética tem um grande peso sobre 0 processo de desenvolvimento, manutenção do crescimento econômico e relação entre os países. Apesar de à primeira vista a questão energética ser mais analisada como um problema de demanda, o setor é interdependente, pois coloca em xeque também quem produz. Nessa perspectiva, países que não produzem ou produzem pequena quantidade de petróleo, gás natural e/ou carvão devem buscar alcançar um patamar previamente calculado e em contínuo crescimento de produção de energias renováveis o que permitirá, inclusive, a abertura de um novo mercado. Diversificação é a palavra-chave de SE onde as fontes de energias renováveis tenderão a converter essa questão em uma nova era de produção e consumo de energia (Dalgaard e Glock, 2009).

Analisando-se a literatura existente sobre a área, percebe-se a dificuldade de uma definição para o conceito de SE que atenda à criação de políticas definidas pelos estados em prol de acolher demandas presentes e, principalmente, de longo prazo. Como os estados só podem garantir aquilo que detêm, SE só pode ser possível, e confiável de se obter, a partir do momento em que o estado é o provedor de suas necessidades; produz grande parte da energia que consome. Sendo assim, o trabalho terá como definição para o termo Segurança Energética:

A capacidade dos estados de assumirem suas demandas energéticas a partir de uma suplementação e/ou produção própria, mesmo que parcialmente dependente de outros países, focado na variedade e no mix energético. ${ }^{3}$

Fora isso, os estados estão sujeitos às inconstâncias do mercado, redução da produção, especulação e retaliações dos países produtores. Fatos estes já observados nos anos de 1973 e 1979 que geraram impactos nas décadas de

\footnotetext{
${ }^{3}$ Definição da pesquisadora.
} 


\section{Universidade Federal Fluminense Instituto de Estudos Estratégicos}

1980 e 1990. Afinal, como garantir a suplementação de suas demandas energéticas senão pela produção própria da energia? Para Yergin (2014), a SE depende do relacionamento entre os países e, portanto, está sujeito a ser uma relação de contínua insegurança. Como a principal função do estado é garantir a sua sobrevivência, um país não pode jamais estar sujeito a outro. A preocupação com o suprimento da demanda energética tem de ser uma inquietação de todos. As já citadas duas crises do petróleo demonstram bem quão insegura pode ser essa relação. Yergin (2014) avalia que:

Seja o que for que seja dito sobre independência energética, a verdade é que há um único mercado petrolífero mundial (...). Além disso, o mercado de energia, como o de comércio e finanças, é cada vez mais internacionalmente interligado. Segurança energética não reside em um domínio de si mesmo, mas é parte de um padrão de relações entre as nações. Como estão essas relações irá determinar quão seguro nós estamos quando se trata de energia.

O termo "energy independence" foi cunhado pelo ex-presidente norte-americano Richard Nixon (1969-1974) em 1973 que novamente deu ênfase à questão em seu Discurso do Estado da União no ano seguinte. Para o então presidente, independência energética significava "a habilidade do país de possuir sua própria energia sem depender de fontes estrangeiras" (Dalgaard e Glock, 2009). Nixon já argumentava a necessidade da criação de fontes alternativas para o petróleo, o gás natural e o carvão mediante à capacidade do próprio país de sanar sua demanda.

Ainda em 1913, quando a Grã-Bretanha estava se preparando para a Primeira Guerra Mundial, Winston Churchill, à época Primeiro Lorde do Almirantado, fez história ao decidir substituir parte do carvão em suas embarcações por petróleo (Dalgaard e Glock, 2009). Não somente as embarcações ficaram mais rápidas como ainda foram necessários menos homens para colocar carvão dentro dos fornos o que permitiu que estes fossem para o convés lutar. A decisão de Churchill foi ao mesmo tempo geopolítica e estratégica: a Grã-Bretanha não ficaria dependente do carvão do País de Gales, nem do fornecimento de petróleo da insegura Pérsia (atual Irã). Apesar do risco associado a essa decisão, Churchill declarou que "Segurança e certeza estão na variedade, e somente na variedade" (ibidem). Mais um exemplo de que o 


\section{Universidade Federal Fluminense Instituto de Estudos Estratégicos}

princípio fundamental da SE deve ser a diversificação de suprimentos ${ }^{4}$. Contudo, o termo independência energética pode ser mal interpretada e visto como autossuficiência. Na verdade, tem muito mais a ver com não vulnerabilidade.

\section{China e (In)Segurança energética}

A crise de energia pela qual passou a China em 2003-2004 confrontou o país a sua instabilidade e ao risco de uma descontínua capacidade de crescimento (Downs, 2006). O corte na energia por todo o país levou a um aumento de $15 \%$ na demanda por petróleo, o que correspondeu a 850.000 barris por dia (bpd). A situação já estava tensa desde 2002 tornando a energia uma questão crucial. Contudo, tratava-se mais de uma dificuldade em manter os níveis do carvão e da eletricidade e não do petróleo. Dependendo mais de $70 \%$ do carvão, sua oferta limitada tornou-se um transtorno e a demanda passou a ser bem maior do que as usinas de geração de energia elétrica e a rede de transmissão podiam produzir. A crise que tomou conta do país atingiu desde a indústria, que teve de trabalhar por meio período, até sinais de trânsito e residências (ibidem). Em pouco tempo o petróleo se viu na posição de substituir o carvão como grande fornecedor de energia o que aumentou a demanda chinesa em 16\% em 2004, acima dos rotineiros $7 \%$ ou $8 \%$.

A perspectiva é de que até 2030 a China amplie seu consumo de energia em 3\% a cada ano, o que fará a demanda por petróleo dobrar para 13.1 milhões bpd (ibidem). Crescendo, desde 2015, a uma média de 6,5\% ao ano ${ }^{5}$, a China está ajustando seu crescimento ao consumo de energia e a sua capacidade de criar políticas que lhe permitam contar com uma, ainda que parcial, autossuficiência interna. Outra questão é que conflitos e crises nos países exportadores de petróleo colocam em dúvida a segurança e contínua oferta. A instabilidade dos países exportadores, o terrorismo jihadista, o forte sentimento de nacionalismo

\footnotetext{
${ }^{4}$ Exemplos bem-sucedidos desta diversificação aconteceram tanto na França quanto no Brasil. Entre 1973 e 1975, sob o mandato dos presidentes Pompidou e Giscard d`Estaing, 13 usinas nucleares foram construídas com capacidade de gerar 1.000 Megawatt. No Brasil, em 1975, quando foi criada a política para a fabricação de motores de automóveis movidos a etanol em vez de gasolina. Hoje os modelos flex são comuns no país, sem contar a possibilidade da instalação de cilindros de gás.

5 Vale ressaltar que para 2020 a taxa de crescimento chinês será impactada pelo COVID - 19. Segundo o FMI, a projeção do PIB chinês é de $1 \%$ para este ano.
} 


\section{Universidade Federal Fluminense Instituto de Estudos Estratégicos}

sobre os recursos naturais, o medo da competição por suprimentos, o custo da energia e as rivalidades geopolíticas passam a ter uma dimensão maior. Atrelando-se ainda a preocupação com o gás natural, devido à dificuldade de construção de gasodutos de longa distância e ao aumento do gás natural liquefeito (GNL), a crise ganhou contornos globais (Yergin, 2014).

Os grandes desafios da China no século XXI são manter sua produção de energia e ao mesmo tempo proteger o meio ambiente dos danos causados pelo alto uso do carvão. Levando-se em consideração que há pouco mais de 10 anos a capacidade de geração de energia chinesa não era mais do que um terço da dos Estados Unidos e hoje os ultrapassa, verifica-se que a produção chinesa dobrou entre 2005 e 2010. De janeiro a fevereiro de 2020 a produção de carvão bruto e energia elétrica para indústrias diminuiu, enquanto a produção de petróleo bruto e gás natural continuou crescendo. A produção de carvão bruto foi reduzida a 490 milhões de toneladas, queda de 6,3\% em relação ao mesmo período do ano passado, e 68,06 milhões de toneladas de carvão foram importadas, um aumento anual de 33,1\% (China, NBS, 2020) .

O consumo atual de carvão na China é de 57,7\% (Chiappini, 2020), inferior aos $77 \%$ de 2005 , mas ainda é o grosso do consumo de energia do país (ibidem). O grande uso do carvão fez a China melhorar sua tecnologia envolvida nas usinas. Elas hoje são mais eficientes, trabalham em níveis elevados de temperatura e pressão com modelos supercritical e ultra supercritical com mais controle da poluição (ibidem) levando as antigas usinas a sair de funcionamento. Apesar da grande discussão ambiental, o carvão ainda será muito utilizado pela China nos próximos anos e, como segundo maior importador mundial, a demanda é reflexo do grande consumo.

\section{Fontes de Energias Renováveis}

Ao longo da década de 1980, o termo "energias alternativas", agora chamadas de energias renováveis, perdeu seu ímpeto impulsionado pela década de 1970 (Yergin, 2014). Comparando e somando custos com a necessidade de empenho em inovação tecnológica, concluiu-se que os gastos com investimento em fontes energéticas renováveis seriam muito altos. A falta 


\section{Universidade Federal Fluminense Instituto de Estudos Estratégicos}

de maturidade tecnológica e a aparente solução da crise do petróleo de 1979, que na década de 1980 baixaram seus preços, fizeram com que na década de 1990 fontes renováveis fossem vistam como uma alternativa incerta e custosa para um futuro longínquo. Contudo, sendo a eletricidade flexível quanto a sua utilização e às formas de geração, ao contrário do petróleo, do gás natural e do carvão, as energias renováveis são versáteis e necessitam de investimento tecnológico criando, assim, um salto inovador para o país que nela investe.

A geração de fontes de energia renováveis aumentou consideravelmente em 2013 e atingiu um recorde de $2,7 \%$ da energia consumida globalmente, acima dos $0,8 \%$ da década anterior. De acordo com relatório do Programa das Nações Unidas para o Meio Ambiente, Pnuma (ONU News, 2020), em 2018 a expansão foi de $7,6 \%$. As fontes renováveis utilizadas na geração de energia cresceram $16,3 \%$ e representaram um recorde de 5,3\% na geração de energia mundial. A China registrou o maior crescimento gradual em energias renováveis, seguido pelos EUA. Fontes renováveis fazem parte de um ambicioso projeto por se tratar de uma questão de segurança energética. Nenhum país pode-se manter, quiçá se desenvolver, sem contar com uma matriz energética que lhe permita um grau mínimo de segurança, ou seja, de autosuficiência. Segundo Palonkorpi (2006), energias renováveis são geralmente produzidas domesticamente o que gera menos risco de serem usadas como pressão políticas.

Os prazos podem ser longos devido à escala e à complexidade do vasto sistema de abastecimento de energia, mas se esta é para ser uma era de transição energética, então o mercado global de energia de US\$ 6 trilhões deve ser "contestável". Ou seja, deve estar disponível aos concorrentes tradicionais empresas de petróleo, gás e carvão, que fornecem a maior parte da energia hoje - e a novatos - empresas de energia eólica, solar e de biocombustíveis -, que desejam uma fatia cada vez maior desse mercado. Uma transição dessa escala, se de fato ocorrer, tem grande significado para as emissões de carbono, a economia como um todo, a geopolítica e a posição das nações (Yergin, pp.14, 2014)

A urgência da China por energia segura, acessível e ambientalmente sustentável para os seus mais de 1,3 bilhão de pessoas é uma questão crucial (Martinot e Junfeng, 2007). Em 2006, o consumo chinês já era o segundo mais 


\section{Universidade Federal Fluminense Instituto de Estudos Estratégicos}

alto do mundo, tendo quase dobrado na última década. O uso de eletricidade está crescendo ainda mais rápido, o dobro desde 2000. Em 2017, o governo anunciou um investimento em energia renovável de US\$360 bilhões até 2020 e suspendeu a construção de 85 usinas de carvão (Woetzel et all, 2017). A China investe duas vezes mais nesse tipo de energia do que os Estados Unidos e mais do que Estados Unidos e União Europeia somados. Ainda segundo o relatório do PNUMA (ONU News, 2020), em 2035 a demanda energética da China deve subir dos atuais poucos mais de $23 \%$ para $28 \%$ em termos mundiais. Em contrapartida, nos Estados Unidos deve cair de 16\% para 12\% (ibidem).

Enquanto a maior parte da eletricidade da China vem do carvão, a utilização crescente de petróleo para a frota veicular tem chamado a atenção. As preocupações com a SE e a escassez de capacidade de energia e poluição do ar estão acrescentando urgência e pressão para melhorar a tecnologia, aumentar o uso de combustíveis alternativos e de energia renovável com o objetivo de se obter mais eficiência energética. As mudanças climáticas também acirraram a pressão sobre a China que em breve ultrapassará os Estados Unidos como o maior emissor de dióxido de carbono a partir de combustíveis fósseis (ibidem). Com grande potencial para o desenvolvimento de fontes renováveis de energia, o governo lançou um conjunto de metas focadas na capacidade de geração a serem alcançadas em 2020. As duas principais fontes são a energia hídrica e a eólica. Com a energia hídrica (China responde por 12\% do mundo das energias hidráulicas) é esperada uma capacidade de 300 GW até 2020. Com a eólica espera-se alcançar uma capacidade de $10 \mathrm{GW}$ (Meisen e Hawkins, 2009).

A Lei de Energia Renovável, promulgada em 2005 e alterada em 2009, defere sobre a contínua expansão das energias renováveis como uma prioridade nacional e criou políticas importantes, incluindo: metas nacionais de energia renovável; uma política obrigatória de conexão e compra; e acordos para compartilhamento de custos e financiamento de incentivos a energia renovável. Em 2015 a China obtinha $8 \%$ de sua energia e 17\% da sua eletricidade a partir de energias renováveis. Em 2018, de acordo com um relatório enviado à sessão bimestral do Comitê Permanente da Assembleia Popular Nacional (APN), a força gerada pela energia renovável totalizou quase 1,87 trilhão de quilowatts-horas (kWh), equivalente a $26,7 \%$ da produção total de energia (Xinhua, 2019). Pelo 


\section{Universidade Federal Fluminense Instituto de Estudos Estratégicos}

ritmo dos investimentos nos últimos $\operatorname{anos}^{6}$ e alcance da produção, a expectativa é de que a China ultrapasse suas metas iniciais de desenvolvimento de energias renováveis em 2020. A potência total de fontes renováveis pode chegar a 400 gigawatts em 2020, quase o triplo dos 135 gigawatts existentes em 2006, com energia hidráulica, eólica, biomassa e solar fotovoltaica fazendo as maiores contribuições (Meisen e Hawkins, 2009).

Alcançar estes resultados dependerá do desenvolvimento da indústria nacional, da disponibilidade de pessoal qualificado, da redução dos custos da tecnologia, da continuação de uma agressiva política por parte do governo, dos níveis de preços adequados e da provisão para geração de energia distribuída por concessionárias de energia elétrica (ibidem). Dado o forte compromisso da China em se tornar um líder mundial na fabricação de energias renováveis, bem como as preocupações sobre a segurança energética, a escassez de energia, a poluição do ar e as alterações climáticas (que 2017 contaram com 0 investimento de US\$126 bilhões em usinas e parques temáticos) as energias renováveis continuarão a ser foco de atenção do país asiático.

O governo chinês tem buscado incluir em sua política doméstica esforços para o desenvolvimento de energia limpa. Entre os objetivos do $13^{\circ}$ Plano Quinquenal para o Desenvolvimento de Energias Renováveis (2016-2020) adotado pela Administração Nacional de Energia a partir de 10 de dezembro de 2016 estão (NAE, 2016):

I. Inserir a participação da energia não fóssil no consumo total de energia primária para $15 \%$ até 2020 e para $20 \%$ até 2030 ;

II. Ampliar a capacidade de energia renovável instalada para $680 \mathrm{GW}$ até 2020;

III. Aumentar a capacidade de vento instalada para $210 \mathrm{GW}$;

IV. Promover o desenvolvimento de energia eólica offshore e oceano;

V. Incentivar a inovação tecnológica em energia renovável, e

VI. Apoiar o desenvolvimento da indústria de energia renovável na China e diminuir a dependência de empresas estrangeiras no domínio.

\footnotetext{
${ }^{6}$ No primeiro semestre de 2018 houve uma redução de $29 \%$ nos investimementos em energia solar em comparação ao mesmo período de 2017. Outra medida foi a divulgação de um documento que restringia projetos subsidiados para a instalação de energia solar. Em energia eólica, o investimento chinês aumentou em $4 \%$ ( $\$ 17.6$ bilhões). No total, foram investidos $\$ 58.1$ bilhões, $15 \%$ menos se comparado ao primeiro semestre de 2017. HENZE, Veronika. Bloomberg NEF Disponível em: $<$ https://about.bnef.com/blog/solar-energy-investment-set-fall-2018-cutback-china-lower-equipment-costs />. Acesso em: 09/02/2019
} 
Como parte do Plano de Desenvolvimento de Médio e Longo Prazo de Energia Renovável, lançado em 2007, o governo fornece financiamento adicional para projetos de pesquisa e taxas fiscais preferenciais para aqueles que estão envolvidos no desenvolvimento e uso de energia renovável. Entre os objetivos estabelecidos estão o de, até 2020 , aumentar para $15 \%$ o uso total de energia de fontes renováveis e em 30\% até 2050 (Sakamoto, 2017). Detalhando por tipo de energia, o Plano aponta para que em 2020 existam 300GW de capacidade hídrica instalada; 30GW para capacidade eólica e o mesmo valor para biomassa, e 1.8GW para energia solar. Houve apelos para o governo ajustar suas políticas para a energia renovável e reduzir as tarifas sobre as importações de equipamentos. "Nova energia é a força motriz para o desenvolvimento sustentável da indústria", disse Liu Zhijia, engenheiro do Centro Nacional de Pesquisa, que está sob controle da Chery Automobile Company. "Nos últimos anos, alguns fabricantes de automóveis nacionais têm investido pesadamente em pesquisa e desenvolvimento de veículos de energia nova", disse ele. Ao longo dos próximos cinco anos, a Chery vai focar no desenvolvimento de veículos de célula de combustível que geram eletricidade por meio de um processo químico que usa combustíveis de hidrogênio e oxigênio do ar (ibidem).

O desenvolvimento de fontes de energia renováveis, como a energia eólica e solar, deve ser intensificada. A proposta sugere também a construção de bases maiores de produção de carvão e adaptação e renovação das minas de carvão de médio e pequeno porte. Para a conservação da água, o governo quer utilizar ainda mais os principais rios e lagos do país e controlar a exploração de água subterrânea (Agência Xinhua, 2017). A China também é a principal fonte de crescimento mundial para a energia hidrelétrica e nuclear. A energia hidrelétrica global aumentou 2,8\% em 2016 em relação a 2015, com mais de 40\% do crescimento provindo da China. Enquanto isso, a energia nuclear global aumentou $1,3 \%$, ou o equivalente a 9,3 milhões de toneladas de petróleo, com a China contribuindo com quase todo o crescimento. De acordo com dados da petrolífera britânica $\mathrm{BP}$, as emissões de carbono no mundo aumentaram ligeiramente em 0,1\% em 2016, enquanto na China, as emissões caíram 0,7\% 


\section{Universidade Federal Fluminense Instituto de Estudos Estratégicos}

em relação a 2015. "As emissões de carbono da China reduziram nos últimos dois anos, depois de crescer mais de $75 \%$ nos 10 anos anteriores, e algumas das melhorias refletem fatores estruturais que provavelmente persistirão" (Chestney, 2010).

\section{Planos quinquenais de desenvolvimento econômico e social}

O primeiro Plano Quinquenal chinês contou com a ajuda do governo soviético e foi iniciado em $1953^{7}$. Nos moldes do modelo econômico da antiga URSS caracterizado pela propriedade estatal, coletivos agrícolas e planejamento econômico centralizado. Os Planos Quinquenais podem ser vistos como uma aplicação da política das Quatro Modernizações na China, proposta por Zhou Enlai, e ratificada por Deng Xiaoping, que almejavam modernizar os setores da agricultura, indústria, ciência e tecnologia e defesa nacional.

O 11ำ Plano Quinquenal (2006-2010) foi o primeiro a inserir como metas o aumento dos espaços verdes, redução da taxa de poluição e preservação dos recursos naturais, melhora na qualidade de vida, proteção ao meio ambiente e diminuição da poluição em $10 \%$ naquele período. A China lançou um programa de ciência e tecnologia dentro do projeto nacional de modo a impulsionar a cooperação internacional em matéria de energias renováveis. De acordo com o projeto, a China desenvolveria novos padrões para intercâmbio e cooperação internacional, encorajaria os países a se comprometerem com as respectivas tecnologias criando assim uma plataforma para a cooperação tecnológica.

O governo priorizou cinco campos de pesquisa, que incluíram a energia solar, a biomassa e combustíveis de energia de biomassa, a energia eólica, a energia de hidrogênio e células de combustível, e os hidratos de gás. Os projetos foram realizados em conjunto pelos Ministérios da Ciência e Tecnologia e do Desenvolvimento Nacional e Reforma. Igualdade de esforços têm sido dado à solicitação de capital privado e de investimento do setor empresarial, especialmente os gigantes energéticos internacionais, para reforçar a cooperação internacional em matéria de energias novas e renováveis (Agência

\footnotetext{
${ }^{7}$ Entre 1963 e 1965 não houve Plano Quinquenal em função de ajuste econômico. Disponível em:< http://chineseculture.about.com/od/historyofchina/a/Chinese-History-Five-Year-Plan.htm>. Acesso em: 24 de junho de 2014.
} 


\section{Universidade Federal Fluminense Instituto de Estudos Estratégicos}

de Notícias Xinhua, 2007). O 17ํㅡㄹ Congresso Nacional do Partido Comunista da China, realizado em outubro de 2007, definiu os objetivos para acelerar a transformação do padrão de desenvolvimento e quadruplicar o PIB per capita das energias renováveis no relatório de status de outubro de 2009 para o ano de 2000 até 2020. O foco é, por meio da otimização da estrutura econômica, melhorar o retorno econômico, reduzir o consumo de energia e proteger o meio ambiente.

O 11ํ Plano estabeleceu ainda as seguintes metas: fornecimento de energia que atendesse a demanda nacional de desenvolvimento econômico e social; realizar progressos significativos na economia de energia, melhorar a eficiência energética, otimizar a estrutura da energia, focar no avanço tecnológico, criar mais benefícios econômicos e competitividade no mercado, macrocontrole da supervisão de mercados, criação de legislação pertinente e sistema compatível com a economia de mercado socialista. O resultado esperado era de que a produção de energia fosse favorável para a economia, a sociedade e o meio ambiente (Junfeng and Lingjuan, 2009).

As políticas chinesas têm sido ambiciosas para a incitação da eficiência energética. No 12ำ Plano Quinquenal (2011-2015) foram fechadas mais de 300 plantas que tiveram baixa eficiência, poluíam muito e produziam pouca energia. Durante o período, a China fortaleceu medidas de controle da quantidade de consumo de energia, estabeleceu um sistema estatístico, contabilístico e de avaliação das emissões de carbono e promoveu um mecanismo de negociação de emissões de carbono baseado no mercado (ibidem). O Plano idealizou a redução do consumo de energia por unidade do PIB, considerada uma medida de eficiência energética, em 16\%. Outra meta era elevar a porcentagem da contribuição das energias renováveis para 11,4\%. Em encontros oficiais realizados no período, principalmente com os Estados Unidos, delineou-se o objetivo de que pelo menos as emissões de carbono não aumentassem, devido a utilização das usinas de energia renovável (ibidem). À época o Greenpeace chegou a analisar que:

O que a China propõe poderia ser conseguido antes, mas é um avanço. Mudar em poucos anos um modelo econômico baseado de forma intensiva em carvão e petróleo sem afetar seu desenvolvimento, em uma economia do tamanho da chinesa, não é tarefa fácil. É histórico dois dos principais poluidores mundiais se comprometam a reduzir suas emissões. 
O 13 Plano Quinquenal (2016-2020) exaltou as chamadas "seis narrativas" da China para o desenvolvimento: China Eficiente, China Equilibrada, China Bonita, China Aberta, China Feliz e Transformando a China. O objetivo era direcionar o país para uma estrutura econômica inovadora e acelerar a atualização industrial com oportunidades de investimento em indústrias emergentes e serviços avançados (RPC, NEA, 2016). O capítulo "Desenvolvimento verde", alerta para a "ecologia em primeiro lugar", com apelo para que o país melhore a qualidade ambiental ao mesmo tempo em que continua se desenvolvendo, abordando questões ambientais e ecológicas; reforçando a proteção ambiental; aumentando a eficiência do uso de recursos naturais; oferecendo produtos mais ecológicos e de alta qualidade para a população em geral; e assegurando um desenvolvimento equilibrado entre 0 aumento da prosperidade para os indivíduos, o crescimento nacional e a visão de uma "China Bonita".

Durante o $13^{\circ}$ Plano, a China tem desenvolvido o mercado de ecoprodutos e ecoserviços, bem como indústrias que têm como foco crescimento e conservação. O programa foi projetado para produzir melhorias tangíveis na qualidade ambiental e formar um modelo de desenvolvimento "verde". Ao atrair capital do setor privado para participar de projetos ambientais, a economia verde e suas indústrias auxiliares são apoiadas por um forte mercado de investimentos (ibidem). A melhoria da eficiência dos recursos e a promoção de estilos de vida ecológicos e de baixa emissão de carbono e métodos de produção indicam oportunidades para investir nos novos setores do mercado ambiental.

\section{Conclusão}

A China é o segundo país mais populoso do mundo e possui uma economia em contínua ascensão pelos últimos 20 anos. Com isso, se transformou no maior consumidor de energia global e a crescente demanda, especialmente por combustíveis líquidos, a tornou extremamente influente, mas também dependente dos mercados mundiais. O país é o segundo maior consumidor de petróleo e gás com companhias petrolíferas espalhadas por todo o mundo. 


\section{Universidade Federal Fluminense Instituto de Estudos Estratégicos}

Também, como a maior consumidora, produtora e ainda dependente do carvão, sofre com o alto grau de poluição em suas cidades, levando à população uma série de doenças de trato respiratórios, cânceres, dentre outras.

Contudo, as atuais reservas de petróleo, gás e carvão não são suficientes para manter a economia chinesa assim como para suprir a demanda para 0 desenvolvimento contínuo a longo prazo. Além de cara e suja, estes tipos de recursos energéticos são escassos e deixam a China dependente da exportação. A eleição do presidente Xi Jinping e do premier Li Keqiang para o período de 2013 - 2023, reafirmaram os passos das administrações anteriores, do ideal de avanço tecnológico definido por Deng Xiaoping e a da garantia da manutenção da economia.

No dia 7 de novembro de 2016, a Administração Nacional de Energia (NEA) lançou o 13을 Plano Quinquenal de Desenvolvimento de Eletricidade para o período de 2016-2020. O documento descreve a principal direção para o setor elétrico chinês e inclui metas específicas de tecnologia, expansão da rede e faz projeções para o crescimento da demanda de eletricidade. As diretrizes são alcançar avanços em tecnologias renováveis, combustíveis fósseis e nucleares, bem como mini-grade, super-grades e redes inteligentes, a fim de aumentar a competitividade do país no setor de energia a nível internacional (NEA, 2017). Melhorar significativamente a inovação em tecnologias, equipamentos, componentes e materiais de energia utilizados em projetos de energia e reduzir a dependência da China de fornecedores estrangeiros de projetos de energia renovável: energia eólica, solar, bioenergia, energia geotérmica e oceânica. Obviamente que o Plano traça objetivos, porém não apresenta as estratégias. Estas são confidenciais e não estão à disposição pública.

A China compreende a importância de tornar-se auto-suficiente energeticamente e busca nesse momento melhorar sua estrutura energética ao mesmo tempo em que investe em energias renováveis. Além de ser uma fonte de energia interna, estas ainda abrem um novo mercado, principalmente no que concerne à energia solar. Hoje a China é o maior produtor e exportador de painéis solares.

Para uma população que continua crescendo, tanto em número populacional (os chineses já estão autorizados a ter dois filhos e o governo estuda liberar essa 


\section{Universidade Federal Fluminense Instituto de Estudos Estratégicos}

questão) quanto em termos de desenvolvimento econômico e comercial, a China precisa estar sempre alguns passos adiante. O país sabe que o isolamento das décadas passadas não gerou frutos positivos no que concerne ao entendimento das políticas chinesas de cooperação e ainda gera desconfiança quanto as suas intenções políticas. Sendo assim, a China está comprometida com seu crescimento econômico, por meio do mix energético, mas também pretende fazer com que ele abra as portas para um comércio sustentável.

\section{Referências}

Acharya, Amitav. 1995. The periphery as the Core: The Third World and security studies. Toronto. Strategies in Conflict: Critical Approaches to Security Studies.

Agência de Notícias Xinhua 13 de novembro de 2007.

Baumann, Florian. 2008. Energy security as multidimensional concept. CAP Policy Analysis, 1: 4-14.

Buzan, Barry. 1991. New Patterns of Global Security in the Twenty-first Century. International Affairs, 67 (3): 431-451.

Buzan, Barry. 2012. Defining International Security Studies. In B. Buzan e L. Hansen (org.), The Evolution of International Security Studies. London: Cambridge University, p. 8-20.

1991. New Patterns of Global Security in the Twenty-first Century. International Affairs, 67(3): 432-433.

Chestney, Nina. 2010. Emissões de CO2 da China subiram 10,4\% em 2010--dados da BP. Portal G1 - Reuters, Rio de Janeiro, 08 jun. 2011. Disponível

em: http://g1.globo.com/mundo/noticia/2011/06/emissoes-de-co2-da-china-subiram104-em-2010-dados-da-bp.html. Acesso em: 10 jan. 2019.

Chiappini, Gabriel. 2020. China gerou mais energia renovável em fase mais crítica da pandemia, mas carvão resiste. Agência EPBR, 12 junho 2020. Disponível em: https://epbr.com.br/china-gerou-mais-energia-renovavel-em-fase-mais-critica-d a-pandemia-mas-carvao-resiste/. Acesso em: 23 set. 2020

INTERNATIONAL cooperation key to renewable energy development. China Daily, Business, Energy. Peking, 13 nov. 2007. Disponível em: http://www.china.org.cn/english/business/231684.htm. Acesso em: 16 mar. 2015. 


\section{Universidade Federal Fluminense Instituto de Estudos Estratégicos}

Dalgaard, K. G., Glock, A. E. C. 2009. The Dialectics of Energy Security Interdependence. Nova York, International Studies Associations Convention.

Downs, Erica. 2006. The Brookings Foreign Policy Studies, Energy Security Series: China,

Brookings Institute, p. 1-67. Downs, E.. The Brookings Foreign Policy Studies Energy Security Series: China. Oil, Gas \& Energy Law Journal 6 (2008), n 6: 1-67.

Henze, Veronika. Solar Energy Investment Set to Fall in 2018, on Cutback in China and Lower Equipment Costs. 2018. Bloomberg NEF, New York, 9 jul. 2018. Disponível em: $<$ https://about.bnef.com/blog/solar-energy-investment-set-fall-2018-cutback-chi na-lower-equipment-costs/>. Acesso em: 09/ fev. 2019.

Junfeng, Li e Lingjuan, Ma. 2009. Background Paper: Chinese Renewables Status Report. Chinese Renewable Energy Industry Association and Renewable Energy Policies Network for the 21st Century. Paris, p.5 - 93.

Karaca, Ragip Kutay. 2012. The impact of China's changing energy strategy to its foreign policy: 1990-2010. Journal of International Relations, 9 (33): 93-118.

Martinot, Eric., Junfeng, Li. e Mastny, Lisa. 2007. Powering China's development: The Role of Renewable Energy. Washington, D.C.: Worldwatch Institute.

Meisen, Peter e Hawkins, Steffanie, 2009. Renewable energy potential of China: making the transition from coal-fired generation. Global Energy Network Institute (GENI), San Diego, California.

Gapon, Sergei. Energia renovável ultrapassou crescimento de fontes fósseis em 2019. ONU News, Belarus, 21 abr. 2020. Disponível em: https://news.un.org/pt/story/2020/04/1711052. Acesso em: 02 de ago. de 2020.

Palonkorpi, Mikko. 2006 The security complex theory and the energy security. In Pieces from peripheries and centres. University of Lapland Reoprts in Education, University of Lapland, Rovaniemi, pp. 302-313.

República Popular da China. 2016. Notice of the 13th Five-Year Plan for Energy Technology Innovation. Issued by the National Energy Agency. National Energy Science and Technology No. 397. National Energy Administration (NEA). Disponível em: http://zfxxgk.nea.gov.cn/auto83/201701/t20170113_2490.htm. Acesso em: 16 de set. de 2017.

República Popular da China. 2004. China Medium and Long Term Energy Conservation Plan November 25, 2004 Disponível em: National Development and Reform Commission. https://policy.asiapacificenergy.org/sites/default/files/China_Energy_Saving_Pla n.pdf

República Popular da China. 2017. Notice of the 13th Five-Year Plan for Energy Technology Innovation. Issued by the National Energy Agency. National Energy 


\section{Universidade Federal Fluminense Instituto de Estudos Estratégicos}

Science and Technology No. 397. National Energy Administration (NEA). Disponível em: http://zfxxgk.nea.gov.cn/auto83/201701/t20170113_2490.htm. Acesso em: 16 de set. de 2017.

República Popular da China. National Energy Administration (NEA). Disponível em:

<http://www.sdpc.gov.cn/zcfb/zcfbghwb/201612/P020161222570036010274.pdf >. Acesso em: 15 de Set. de 2017.

República Popular da China. National Development and Reform Commission (NDRC). 2016. (In)Segurança Energética. National Energy Administration (NEA). Disponível em: < http://www.gov.cn/xinwen/2016-06/01/ content 5078628.htm>.

República Popular da China. National Energy Administration. 2016. Comissão Nacional de Desenvolvimento e Reforma. Aviso sobre o 13ํㅗ Plano Quinquenal de Desenvolvimento de Energia Renovável. Energia de Desenvolvimento e Reforma. No. 2619

Disponível em: <http://www.nea.gov.cn/2016-12/19/c_135916140.htm>. Acesso em: 23 de julho de 2016.

República Popular da China. 2016. The State Energy Administration on the issuance of the "Energy Technology Innovation". 13th Five-Year Plan notice of national energy science and technology. National Energy Administration (NEA). No. $397 . \quad$ Disponível em: http://zfxxgk.nea.gov.cn/auto83/201701/t20170113_2490.htm. Acesso em: 16 set. 2017.

República Popular da China. 2017. National Energy Administration (NEA). Disponível em: <http://www.sdpc.gov.cn/zcfb/zcfbghwb/201612/P020161222570036010274.pdf >. Acesso em: 15 de Set. 2017.

RE100 China Analysis. China's Fast Track to a renewable future. 2015. Disponível:

https://www.theclimategroup.org/sites/default/files/archive/files/RE100-China-an alysis.pdf. pp. 13. Acesso em: 21 jul. 2017.

República Popular da China. 2020. Energy production in the First Two Months of 2020. National Bureau of Statistics of China. 2020. http://www.stats.gov.cn/english/nbs/200701/t20070104_59235.html

República Popular da China. 2016. The National Development and Reform Commission on the issuance. Notice of the 13th Five-Year Plan for Renewable Energy Development. TD Energy No. 2619. Energy Information Administration. Disponível em: <http://www.nea.gov.cn/2016-12/19/c_135916140.htm>. Acesso em:

Sakamoto, Camila. 2020. Energias Renováveis e o Investimento Chinês. 2017. 


\section{Universidade Federal Fluminense Instituto de Estudos Estratégicos}

REIS, Alan. Energias Renováveis e o Investimento Chinês. China Link Trading. São Paulo, 13 jan. 2017. Disponível em: http://www.chinalinktrading.com/blog/energias-renovaveis-investimento-china/. Acesso em: 25 jul. 2018.

CHINA investirá US\$360 bi em energias renováveis até 2020. Portal G1, Rio de Janeiro, $1^{\text {o }}$ maio $2017 . \quad$ Disponível em: https://g1.globo.com/economia/noticia/china-investira-us-360-bi-em-energias-re novaveis-ate-2020.ghtml. Acesso em: 3 dez. 2018.

GAPON, Sergei. Energia renovável ultrapassou crescimento de fontes fósseis em 2019. ONU News, Brasil, 21 abr. 2020. Disponível em: https://news.un.org/pt/story/2020/04/1711052. Acesso em: 17 set. 2020.

Stone, Marianne. 2009. Security According to Buzan: A Comprehensive Security Analysis. Security Discussion Papers Series 1.

Yergin, Daniel. 2006. Ensuring Energy Security. Foreign Affairs, 85 (2): 69-82

Yergin, Daniel. 2014. A Busca: Energia, Segurança e a Reconstrução do Mundo Moderno. Rio de Janeiro: Intrínseca.

CHINA leads global efforts in clean energy expansion. Xinhuanet News Agency. Pequim, jul. 2017. Disponível em: http://news.xinhuanet.com/english/2017-07/12/c_136437759.htm. Acesso em: 10 jul. 2017.

CHINA launches week-long campaign to promote energy conservation. Xinhuanet News Agency. Pequim, 11 jun. 2017. Disponível em: http://news.xinhuanet.com/english/2017-06/11/c_136357275.htm. Acesso em: 11 jul. 2017.

CHINA leads global efforts in clean energy expansion. Xinhuanet News Agency. Pequim, 12 jul. 2017.2 Disponível em: http://news.xinhuanet.com/english/2017-07/12/c_136437759.htm. Acesso em: 10 nov. 2017.

APLICAÇÃO da lei promove utilização de energia renovável na China. Xinhua Português. Pequim, 25 dez. 2019. Disponível em: http://portuguese.xinhuanet.com/2019-12/25/c_138656469.htm. Acesso em: 02 jan. 2020.

Woetzel, Jonathan et all. 2017. How technology is reshaping supply and demand for natural resources. McKinsey Global Institute:1-104 